\title{
SINGLE RETINAL GANGLION CELL RESPONSES IN THE DARK-REARED RAT: GRATING ACUITY, CONTRAST SENSITIVITY, AND DEFOCUSING
}

\author{
Maureen K. Powers' ${ }^{1}$ and Daniel G. Green \\ Vision Research Laboratory, University of Michigan, Ann Arbor, Michigan 48109, U.S.A.
}

(Received 2 November 1977; in revised form 27 February 1978)

\begin{abstract}
The visual acuity, refractive state, and depth of focus of the dark-reared hooded rat's darkadapted eye were determined by recording the responses of retinal ganglion cell axons in the optic tract. The smallest square-wave grating to which the units responded subtended $0.22 \mathrm{c} / \mathrm{deg}$. The contrast sensitivity function for sine-wave gratings peaked at $0.02-0.07 \mathrm{c} / \mathrm{deg}$. Corrective lenses of $\pm 14 \mathrm{D}$ reduced the responsiveness of optic tract units to $100 \%$ contrast square-wave gratings by only $20 \%$, implying (1) that objects from $7 \mathrm{~cm}$ in front of the eye to optical infinity are in equivalent focus, and (2) that the depth of focus of the rat's eye is enormous.
\end{abstract}

Key Words-rat; retinal ganglion cells; refraction; acuity; depth of focus: modulation transfer function

\section{INTRODUCTION}

Every measurement of the refractive state of the rat's eye has yielded different results. Published estimates range from $12.5 \mathrm{D}$ myopic (Lashley, 1932) to $17 \mathrm{D}$ hyperopic (Massof and Chang, 1972), with many intermediate values (Brown and Rojas, 1965; Siminoff, Schwassmann and Kruger, 1966; Montero, Brugge and Beitel, 1968; Block, 1969; Shaw, Yinon and Auerbach, 1975; Wiesenfeld and Branchek, 1976; Green, Tong and Cicerone, 1977; Hughes, 1977; Meyer and Salinsky, 1977).

That so many different laboratories have tried to assess the refractive state of the rat's eye attests to the importance of the measurement as well as to its elusiveness. It is clearly important to know where stimuli must be placed in order to be in focus on the retina; or, alternatively, especially in electrophysiological experiments, what optical correction would result in best focus. Measurements of receptive field size and acuity, for example, could be greatly altered by out-of-focus stimuli.

We report here the results of experiments we designed to try to clarify this issue. The rats were exposed only to dim red light during rearing, and they were tested under scotopic conditions; the first factor was intended to maximize the probability that the retinas were not light-damaged at the time of testing, and the second was intended to provide levels of illumination that would typically be encountered by a nocturnal animal.

In these experiments we determined the grating acuity of each single retinal ganglion cell we encountered while recording from it extracellularly. We then put human contact lenses of different powers in front of the eye, and measured their effect on the same unit. While the acuity we found was slightly less than

${ }^{1}$ Current address: Department of Psychology, N1-25, University of Washington, Seattle, Washington 98195, U.S.A. that which others have observed, we could not improve it with lenses. Neither was it made much worse by lenses of $\pm 14 \mathrm{D}$. Although this result may not seem to be a clarification, we will argue elsewhere (Green, Powers and Banks, 1978) that an apparently afocal system is not surprising in a small eye where the depth of focus is very large.

\section{METHODS}

\section{Subjects and surgical preparation}

Five female $(215-360 \mathrm{~g})$ and three male $(365-370 \mathrm{~g})$ Long-Evans hooded rats from our colony were the subjects in this study. They were raised in the dark and experienced only occasional dim red illumination.

Surgery was carried out under dim red light or with the experimental eye covered with an opaque contact lens. Animals were anesthetized with urethane $11.5 \mathrm{~g} \mathrm{~kg}$ body weight maximum dose, in physiological saline solution. injected intraperitoneally). A tracheal cannula was inserted. In some animals a cannula was also placed in the carotid artery in order to monitor blood pressure. All animals had a cannula in the femoral vein, through which a solution containing $10 \mathrm{mg} / \mathrm{kg}$ per $\mathrm{hr}$ gallimine triethiodide (Flaxedil), $0.67 \mathrm{mg} / \mathrm{kg}$ per hr tubocurarine chloride, $30 \mathrm{mg} / \mathrm{kg}$ per $\mathrm{hr}$ urethane and $1.0 \mathrm{~cm}^{3} / \mathrm{kg}$ per hr $5 \%$ dextrose in saline was continually infused.

The rat was placed in a stereotaxic device (Baltimore Instruments), and an anal thermistor probe (YSI-Sostman Model 73A), which monitored body temperature and controlled it by regulating a heating pad beneath the animal, was inserted. The eyelids were gently retracted with surgical silk threads, and a drop of $1 \%$ atropine sulfate was topically applied to the eye to dilate the pupil. Measurements using a small pupil were made either before the atropine was given or with an artificial pupil of $1.0 \mathrm{~mm}$ diameter. We wanted to avoid deforming the globe in any way, and therefore did not use an eye stabilization ring. Although the rat was paralyzed during the experiments, slow drifts in the eye's position almost certainly occurred (Cicerone and Green, 1977). But because our stimuli more than covered the receptive field (see below), and because 
we frequently monitored the position of the receptive field. drifts in the position of the eye were unlikely to have affected the results

The skull was opened and the optic tract located with a metal alloy-filled glass mictopipette (Gesteland. Howland. Lettvin and Pitts, 1959), as described before (Green et al. 1977). Then a tungsten microelectrode (Levick. 1972) was lowered at the same coordinates until a single unit was isolated. During both these procedures (locating the optic tract and isolating single units), a half ping-pong ball was in front of the rat's eye. This served as a diffuser for the preliminary light stimuli we used: $0.5 \mathrm{sec}$ flashes of white light every $2.5 \mathrm{sec}$, or a low spatial frequency grating that drifted at $1 \mathrm{~Hz}$. We studied every unit encountered by the microelectrode. regardless of its response properties or retinal location. The rat was rotated on a turntable until the unit's receptive field fell within the range of the stimulator.

\section{Stimulus}

$0.01-0.1 \mathrm{~mL}$ gratings were produced on the face of an oscilloscope (Campbell and Green. 1965) and focused with a lens on a rear projection screen. The screen was $20-40 \mathrm{~cm}$ from the eye. depending upon the location of the receptive field. The green grating ( $P 31$ phosphor) completely covered the receptive field and drifted at $1 \mathrm{~Hz}$ independent of its spatial frequency. Square-wave gratings were used in the acuity and refraction studies, and sine-wave gratings in the contrast sensitivity experiment. All gratings were $100^{\circ}{ }_{0}$ contrast except in the contrast sensitivity experiment. The refractive power of the eye was varied by placing human corneal contact lenses as close as possible to the eye (but not touching it). They were held in place with surgical tape. The lenses were $6-8 \mathrm{~mm}$ in diameter, and the power of each was measured at least twice with a contact lensometer.

\section{Data collection and analysis}

A mini-computer (Data General NOVA) recorded the occurrence of action potentials and generated poststimulus time histograms. The start of a histogram was phase-locked to the stimulus so that all trials began when the dark and light portions of the grating were in the same position relative to the receptive field. The histograms were displayed on a graphics terminal (Tektronix 4010 ) and or printed out by a teletype (Texas Instruments Silent 700 ).

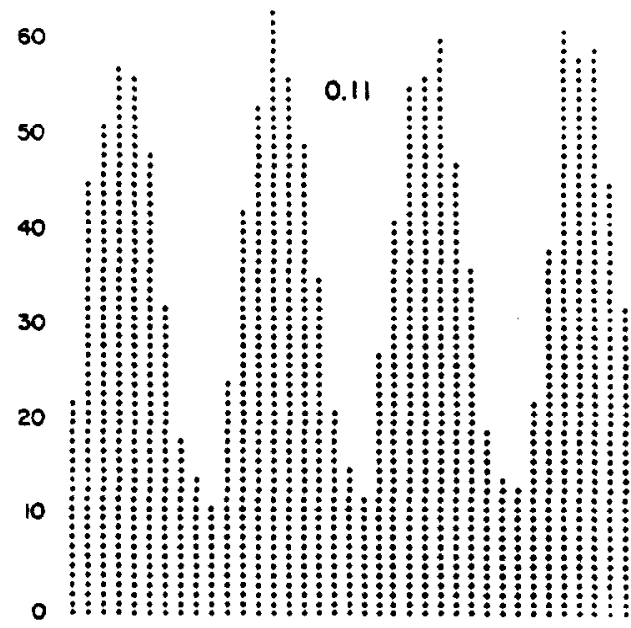

\subsection{5}

50

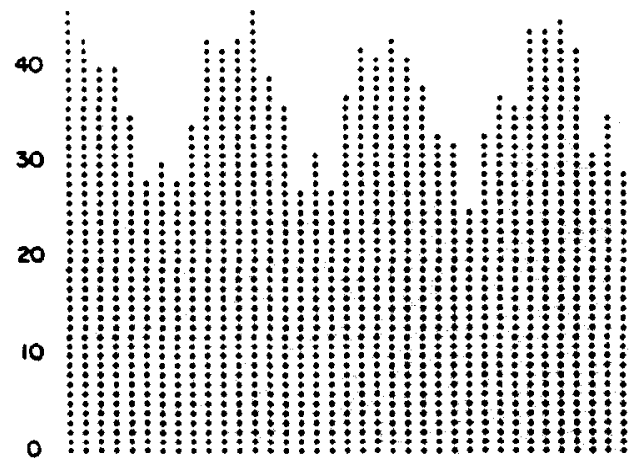

0.17

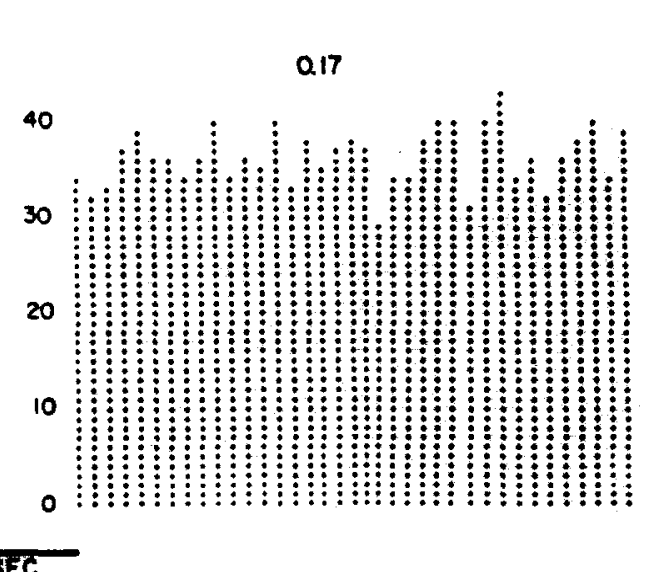

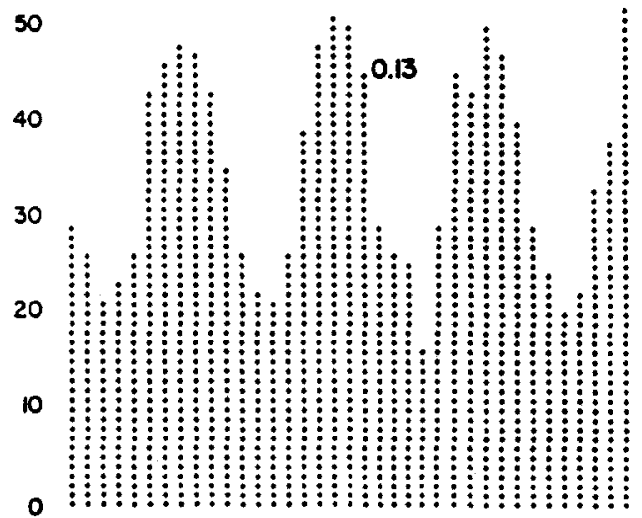

\section{TSEC}

Fig. 1. Sample histograms from an optic tract fiber. The number of spikes tabulated by computer and summed over 10 trials is shown as a function of the phase of the square-wave grating drifting at $1 \mathrm{~Hz}$ through the receptive field. Each histogram was recorded at a different spatial frequency: indicated in c/deg. Although the histograms do not all begin at the same phase location. once the response during the first trial had been recorded. all subsequent trials added to that histogram began at the same phase location. The unit depicted here responded in a manner typical of X-cells (cf. Enroth-Cugell and Robson. 1966): that is, it maintained a similar mean firing rate regardless of the spatial frequency of the stimulus. Other units fired only when light (or dark) bars entered their receptive fields, as Y-cells would be expected to do (cf. Enroth-Cugell and Robson, 1966). The mean firing rate of such units tended to increase with increasing spatial frequency of the stimulus. 
Each histogram was the sum of ten trials. 2 cycles/trial. Examples of the raw data appear in Fig. 1. The response measure we chose was the difference in the mean number of spikes at the peaks and troughs of a given histogram. This value was estimated graphically from the histograms.

A difference of ten spikes. equivalent to an average of one per trial. was called threshold: this value was rarely attained through random variations in baseline firing. yet was low enough to be barely noticed as a response upon visual inspection of the histograms. For example, the response to the $0.15 \mathrm{c} / \mathrm{deg}$ grating in Fig. 1 is clear, while it is equally clear that there is no response to the $0.17 \mathrm{c} / \mathrm{deg}$ grating. The peak-trough values we measured from these two histograms were 16 and 9. respectively. A difference of 10 spikes also tended to correlate with the experimenters subjective auditory criteria. If none of the test stimuli produced exactly 10 spikes, threshold was determined by interpolating linearly, from graphed data between the two stimuli that produced just more and just less than 10 spikes peak-to-trough difference.

\section{RESULTS}

\section{Acuity}

The number of action potentials recorded depended upon the spatial frequency of the grating. Figure 2 shows results from several typical units. The mean acuity for all 23 units was $0.22 \mathrm{c} / \mathrm{deg}$, with a standard deviation (s.d.) of 0.08 . That is, one cycle of the grating covered $4.55^{\circ}$ of the visual field at threshold, on the average. The range of threshold values was $0.09-0.40 \mathrm{c} / \mathrm{deg}$, or 2.5-11 degrees per cycle.

The variability in our data is primarily due to differences between animals, and not between different units from the same animal. This point is illustrated in Table 1, which lists the average threshold grating for each rat. Note that most standard deviations were less than 0.08 , the value we found when thresholds for all individual units were averaged (see above). We

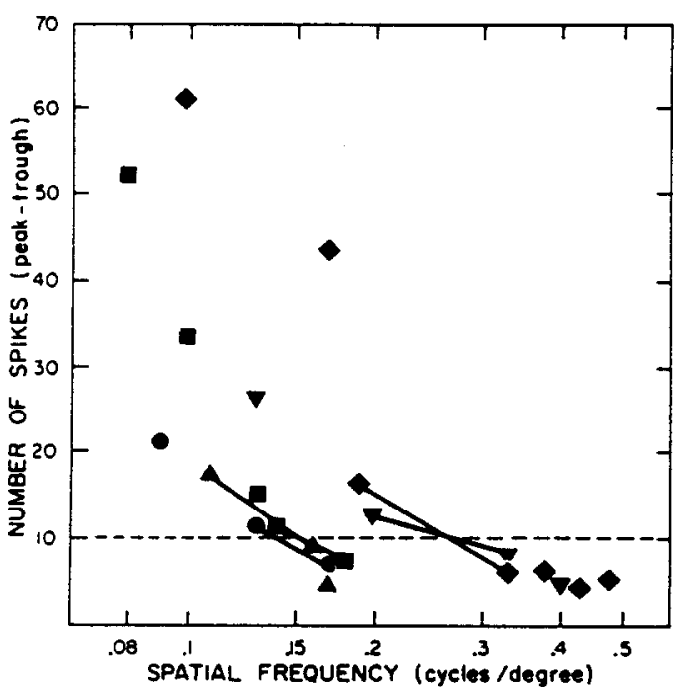

Fig. 2. Spatial acuity for square-wave gratings in optic tract fibers. Different symbols represent different units. Diamonds: $1 / 11 / 77$ unit 1 : squares: $1 / 11 / 77$ unit 3 : circles: 6/7/77 unit 4; inverted triangles: 6/29/77 unit 1 ; upright triangles: $6 / 29 / 77$ unit 5 . The number of spikes fired was determined from histograms, like those in Fig. 1. by subtracting the average number that occurred during troughs from the average number that occurred during peaks. Ten spikes (i.e. one per trial) was considered threshold.
Table 1. Mean visual acuity of units from individual rats

\begin{tabular}{cccc}
\hline $\begin{array}{c}\text { Rat } \\
\text { (date) }\end{array}$ & $\begin{array}{c}\text { Mean threshold } \\
\text { grating (c/deg) }\end{array}$ & $\begin{array}{c}\text { Number } \\
\text { of units }\end{array}$ & $\begin{array}{c}\text { Standard } \\
\text { deviation }\end{array}$ \\
\hline $11 / 26 / 76$ & 0.33 & 3 & 0.08 \\
$12 / 14 / 76$ & 0.29 & 3 & 0.01 \\
$12 / 23 / 76$ & 0.17 & 1 & - \\
$1 / 4 / 77$ & 0.20 & 3 & 0.04 \\
$1 / 11 / 77$ & 0.22 & 5 & 0.05 \\
$3 / 15 / 77$ & 0.17 & 3 & 0.01 \\
$6 / 7 / 77$ & 0.12 & 2 & 0.04 \\
$6 / 29 / 77$ & 0.20 & 3 & 0.09 \\
\hline
\end{tabular}

assume the variability in acuity is a reflection of inherent individual differences, because there were no obvious external differences (such as lens opacities) among the animals.

Using the individual threshold measurements, we found no statistically significant relations between acuity and sex $(t=0.43$, d.f. $=21)$, body weight $(t=0.46, \mathrm{~d} . f .=21$, when animals weighing more than $300 \mathrm{~g}$ were compared to those weighing less than $300 \mathrm{~g}$ ), or the center response type of the unit, i.e. on or off $(t=1.44$, d.f. $=16, P \leq 0.1)$. While there were likewise no obvious correlations between acuity and the size and retinal location of the receptive fields, our measurements of receptive fields were not careful enough to rule out these possibilities.

To assure ourselves that the low acuity we measured was not due to an inadvertent selection of suboptimal stimuli, we tested the effect of two stimulus parameters on the acuity measurements. The first was luminance. We found that while the number of spikes recorded at any given spatial frequency depended upon the mean luminance of the grating, the threshold spatial frequency was not significantly correlated with luminance $(r=-0.34)$ within the range we tested (about \pm 1 log unit from our usual test value). The second parameter tested was the temporal frequency of the grating. We found no systematic variation in the peak-to-trough measurements between 0.5 and $5.0 \mathrm{~Hz}$.

During the course of other experiments in our laboratory, we have used a plano rat contact lens to prevent desiccation of the cornea, and a small artificial pupil to minimize the effect of any refractive error (see Green et al., 1977). At the time the earlier studies were done, we had little evidence that these devices had no effect on the response of optic tract units. In the present experiment, we tested the effects of both the rat contact lens and the size of the pupil on acuity, and found that neither changed it systematically.

\section{Contrast sensitivity}

The solid symbols in Fig. 3 show contrast sensitivity as a function of spatial frequency for three units. Peak sensitivity for all three units was $0.03-0.07 \mathrm{c} / \mathrm{deg}$. The high-frequency limit for resolution of sine-wave gratings, estimated from the data in Fig. 3, was about $0.2 \mathrm{c} / \mathrm{deg}$, which is close to the value we found to be the limit for resolution of square-wave gratings (see above).

The open circles in Fig. 3 show the relative amplitude (peak minus trough) of one unit's response to 


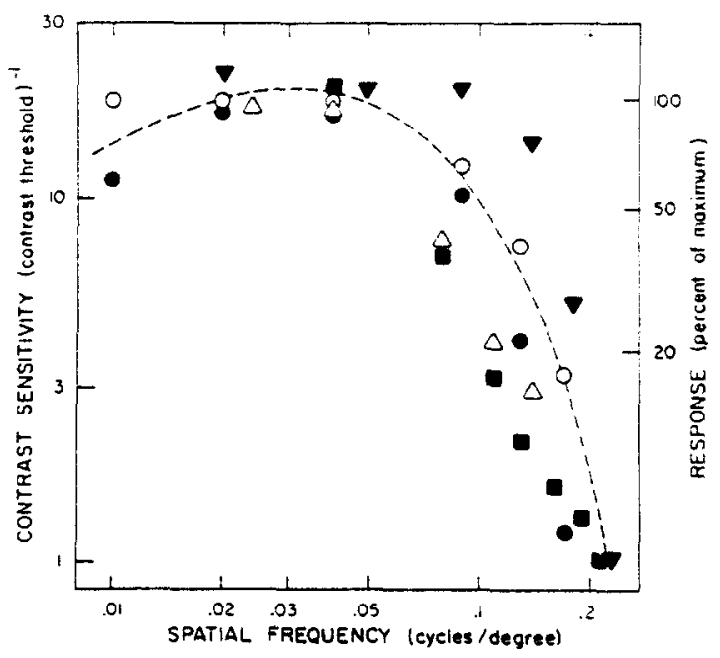

Fig. 3. Modulation transfer functions for sine-wave gratings. Filled symbols (left ordinate) show the reciprocal of contrast threshold. where contrast sensitivity of $10=$ threshold contrast of $10^{\circ} \%$ Open symbols (right ordinate) show percent of maximum response when contrast was constant. The open circles show percent response at $50^{\circ}{ }_{\circ}$ contrast. and the open triangles at $100 \%$ contrast. The smooth curve has been drawn by hand to fit the data. Different shaped symbols represent different units: filled and open symbols of the same shape are data from the same unit. Inverted triangles represent data from $1 / 11 / 77$ unit 1C: all other symbols same as in Fig. 2. a sinusoidal grating when spatial frequency was varied. In this case, the contrast of the grating was held constant at $50 \%$. The peak response has been shifted along the vertical axis to coincide with peak contrast sensitivity. Comparing these measurements with the contrast sensitivity function determined on the same unit (solid circles) shows that the two curves have similar shapes. Thus, for this unit the amplitude of response to a $50 \%$ contrast grating varied with spatial frequency in the same way as the sensitivity to contrast varied with spatial frequency.

The relative response amplitude of another unit was measured for various spatial frequencies, but this time the contrast of the grating was $100^{\circ}$. The curve is similar to the contrast sensitivity function represented by solid squares (another unit).

We applied a silicon fluid (Dow Corning 360 Medical Fluid, 20 csks viscosity) to the cornea, such as might be done to prevent its drying (e.g. Montero et al., 1968), while still recording from one of the units in Fig. 3. The resulting contrast sensitivity function was indistinguishable from the original one. This result demonstrates that. for the rat at least, the application of silicon fluid of this viscosity does not affect contrast sensitivity.

\section{Refraction}

The effect of strong lenses on the response of several units is shown in Fig. 4. The dotted line connects data from a typical unit. Although the response was best with a correction of $\pm 10 \mathrm{D}$. it was reduced by only $5 \%$ when no correction was imposed. Further.

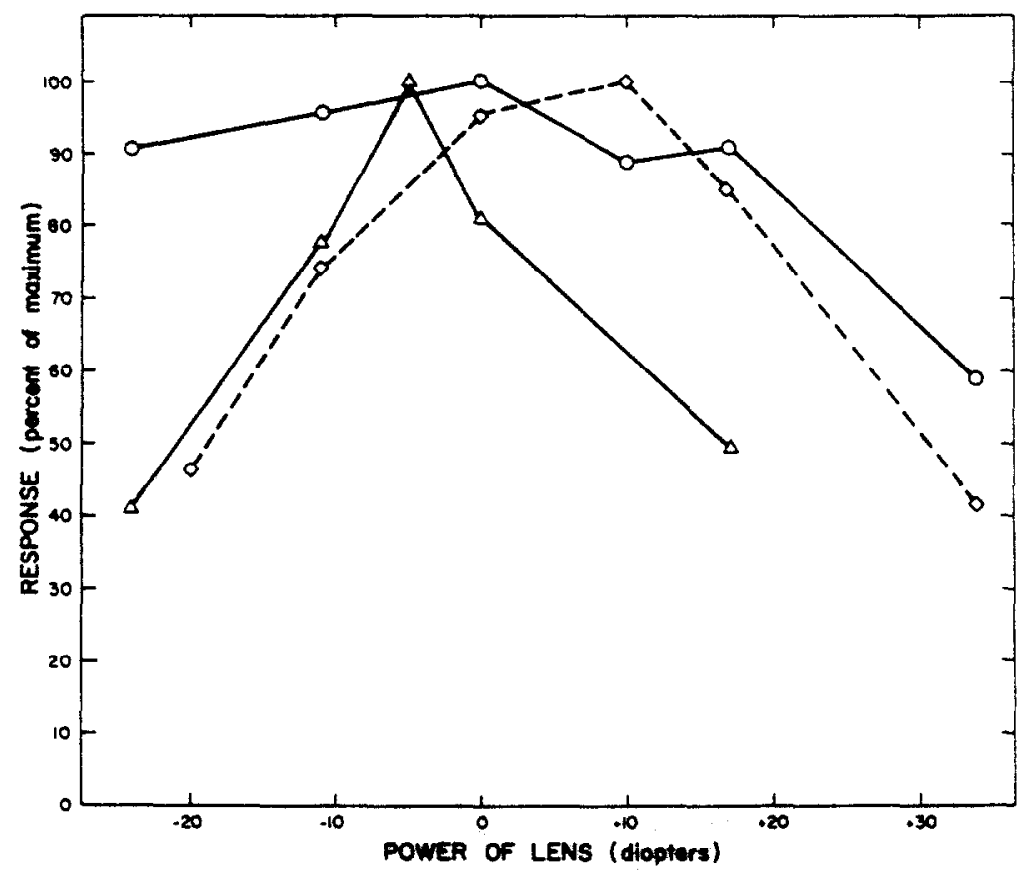

Fig. 4. Effect of focus on units in rat optic tract. The dotted line is a typical unit: athough the data plotted were obtained before the pupil was dilated. the curve we obtained for the same unit after dilating the pupil was very similar. The two solid lines connect data from a unit with a flatter profile (obtained before the pupil was dilated). and one with a sharper profile (obtained with a dilated pupil). These refractions were all done with $100 \%$ contrast square-wave gratings at suprathreshold spatial frequencies (circles $0.04 \mathrm{c} / \mathrm{deg}$ : triangles $0.12 \mathrm{c} / \mathrm{deg}$ : diamonds $0.14 \mathrm{c} / \mathrm{deg}$ ). MTF's and acuities for the units represented by circles and diamonds were plotted in the previous two figures. using the same symbols. Upright triangles show data from $3 / 15 / 77$ unit 2 . 


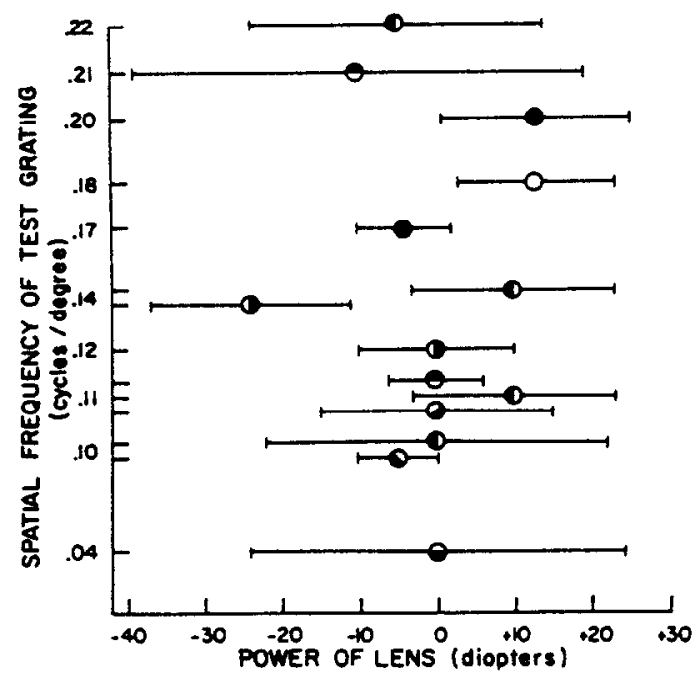

Fig. 5. Dioptric range of best response by single optic tract fibers during refraction. Ordinate: spatial frequency of the square-wave grating used during the test in $\mathrm{c} / \mathrm{deg}$ (not to scale). Abscissa: power of lenses, in diopters. The symbols show the point of maximum response for each unit, and the bars show the range over which the response of each unit reached at least $80 \%$ of its maximum. Similar symbols represent units from the same animal. Open circle $11 / 26 / 76$, closed circles $12 / 14 / 76$, lower right half filled $12 / 23 / 76$, right half filled $1 / 4 / 77$, left half filled $1 / 11 / 77$, lower left half filled $3 / 15 / 77$, lower half filled $6 / 7 / 77$, upper half filled $6 / 29 / 77$. One unit, recorded on $1 / 11 / 77$, was tested at two different spatial frequencies, 0.22 and 0.14 : both points are shown in this figure.

the magnitude of the response was reduced by no more than $20 \%$ (or $0.1 \mathrm{log}$ units) over a range of $26 \mathrm{D}$. Note that a $20 \%$ reduction in response also corresponds to only about $0.1 \log$ unit reduction in contrast sensitivity (see Fig. 3).

Some units were affected even less by the insertion of lenses. The data from one such fiber are represented by open circles in Fig. 4 . The response of this unit remained at $80 \%{ }^{2}$ maximum or better from $-24 \mathrm{D}$ to $+22 \mathrm{D}$. A few units were affected more than average, and the filled triangles show data from one representative of this group; the range for $80 \%$ maximum response was about $10 \mathrm{D}$. Neither the size of the pupil nor the presence of the rat contact lens had any consistent influence on these responses. Likewise, there was no consistent influence of retinal location or class of unit (i.e. "sustained" or "transient") in our sample.

We refracted a total of 13 units. Figure 5 summarizes the results from them. There was no clear relation between the spatial frequency of the test grating (which was always above threshold) and the response. The same unit tested at both 0.14 and $0.22 \mathrm{c} / \mathrm{deg}$ (its threshold was $0.29 \mathrm{c} / \mathrm{deg}$ ) had a similar range of best response at each, and the unit tested at 0.22 -the highest spatial frequency-had a similar range to the

\footnotetext{
${ }^{2}$ We have used $80 \%$ maximum (instead of, for example $90 \%$ ) to indicate the range of response because random fluctuations in baseline measurements approached $10 \%$ (See Methods and Fig. 1).
}

unit tested at the lowest spatial frequency -0.04 (its threshold was $0.14 \mathrm{c} / \mathrm{deg}$ ).

The mean correction that resulted in the maximal response from the units in Fig. 5 was $-0.14 \mathrm{D}$. If the distance from eye to screen $(20-40 \mathrm{~cm})$ is taken into account, the refractive error of these units was about -2.6 to $-5.1 \mathrm{D}$, or $3-5 \mathrm{D}$ of myopia. However. notice the size of the range over which the response was at least $80 \%$ of maximum: it averaged $\pm 14.07 \mathrm{D}$. with a standard deviation of $7.14 \mathrm{D}$. The slight myopia indicated by our results is very small by comparison.

\section{DISCUSSIO:}

The responses of retinal ganglion cells have been used by others to determine the acuity and refractive state of fish eyes (Meyer and Schwassmann. 1970; Schwassmann, 1975), and the results have been reported to compare well with behavioral measurements of acuity in the same animals (see Schwassmann, 1975). Our results in the dark-reared rat agree reasonably well with others in the estimation of this animal's visual acuity, and we will argue below that they are not inconsistent with estimates of refractive error made by others.

\section{Acuity of the hooded rat}

The resolving power of our sample of rat retinal ganglion cells, $\frac{1}{3}-\frac{1}{1 !} \mathrm{c} / \mathrm{deg}$, is consistent with the size of receptive fields of ganglion cells measured in our laboratory and elsewhere. The width of the plateaus of sensitivity profiles in dark-adapted units averages about $6^{\circ}$, and the range is about $3-12^{\circ}$ (cf. Green et al., 1977). Brown and Rojas (1965) found receptive field centers of very similar dimensions $-2.7^{\circ}-9^{3}$. Partridge and Brown (1970) report centers of $3^{\circ}-10^{\circ}$, and they observed no change in receptive field organization with intensity. This correlation between acuity and receptive field size was not unexpected, and it tends to support the validity of our measurements.

The behaving rat is able to resolve finer gratings than our results would predict. Estimates of maximum acuity range from $0.5 \mathrm{c} / \mathrm{deg}$ (Lashley, 1930; Wiesenfeld and Branchek, 1976) to about $1.0 \mathrm{c} / \mathrm{deg}$ (Lashley, 1938; Hermann, 1958). All of these authors used light-adapted rats, however, and the lightadapted ERG has revealed the presence of cones in the rat retina (Green, 1971, 1973). Although there are probably very few of them. cones are responsible for the ERG recorded in rats with no (or very few) rods (Cicerone, 1976), and their influence might be responsible for the higher acuity in the behavioral experiments. Unfortunately, the gratings we used could not be made intense enough to measure acuity at photopic levels.

\section{Refractive error}

The range of focal planes that results in optimal response from rat retinal ganglion cells is very large, and almost certainly includes the natural focal plane of the eye (cf. Fig. 5). We infer from this that the rat's eye is emmetropic, in the sense that ganglion cell responses to objects at infinity are not significantly improved with supplemental lenses. 
Ikeda and Wright (1972) have reported that sustained-type ganglion cells in cat respond differently to induced refractive error than do transient type cells. Our evidence suggests that both types of unit in the rat respond similarly to induced refractive error. It must be emphasized that our sample is small, however. and does not allow us to eliminate the possibility that some differences between the types of ganglion cell do exist.

Our finding that the eye is essentially emmetropic does not, at first glance. seem to agree with the results of other investigators. However, we also found that ganglion cells responded equivalently over a range of $\pm 14 \mathrm{D}$ of optical correction. Hence we believe that our results are in fact consistent with those of any other study that found refractive errors between $14 \mathrm{D}$ myopia and 14D hyperopia. Nearly all previous measurements fall in or close to this range. The only exception is one that indicates extreme hyperopy (Massof and Chang. 1972) which was made retinoscopically and ophthalmoscopically-methods that have been postulated to exaggerate refractive error in the hyperopic direction in small eyes (Glickstein and Millodot. 1970).

Three measurements are sufficiently similar to ours to warrant separate attention.

Brown and Rojas (1965) found that the size of receptive field centers of retinal ganglion cells was minimized when the screen upon which stimuli were presented was $40 \mathrm{~cm}$ from the eye. This corresponds to $2.5 \mathrm{D}$ myopia, a value very similar to ours.

In a recent study, Meyer and Salinsky (1977) reported that rats whose body weights were similar to ours were $1.4 \mathrm{D}$ myopic with a fully dilated pupil. They obtained this value by recording the amplitude of the visually-evoked cortical potential to a large grating of $0.2 \mathrm{c} / \mathrm{deg}$ when trial set lenses of various powers were positioned $3 \mathrm{~mm}$ from the eye.

In another recent study, Hughes (1977) has examined the relation between the receptive field diameter of retinal ganglion cells and refractive error induced by placing spectacle lenses close to the eye. He found that when the pupil was small, the receptive field changes with refractive error were so slight that the measurements could not be used to identify the best corrective lens. He argues from optometric refraction, however, that the eye with a small pupil must be nearly emmetropic. This conclusion does not differ from ours. His measurements with a fully dilated pupil, on the other hand, are different from ours; they indicate a clear minimum at $+10 \mathrm{D}$ of induced refractive error in the four units illustrated (see his Fig. 7). While some of our units did, like his, respond best with optical correction. the number in our sample that responded best with plus correction was nearly equal to the number that responded best with minus correction (see our Fig. 5).

Hughes suggests that the hyperopia he finds when the pupil is large is due to aberrations in the peripheral optical apparatus, but we find no systematic effect of the size of the pupil on refractive state. We have no satisfactory explanation for the discrepancy between our results and his. but we suggest that differences in the spatial frequency content of the test targets may be important. This suggestion comes from the observation that the refractive state of the human eye with a dilated pupil depends on the spatial frequency content of the test target iGreen and Campbell. 1965). From a Fourier standpoint a small spot of light. such as used by Hughes (19-7), is a different and more complex stimulus than a grating. Lising high frequency gratings both we and Meyer and Salinsky (1977) find the animals to be slightly myopic. not hyperopic.

There are two other factors that might be responsible for the differences between our results and those of Hughes (1977). First. his rats were of the D.A. (agouti) strain. whereas ours (and those of Mever and Salinsky. 1977) were the Long-Evans hooded variety. Second. he selected only on-center sustained type ganglion cells with minimally influential surrounds, while we recorded from many different types.

Although Meyer and Salinsky's (1977) study agrees nicely with ours in the measurement of refractive error, the curves they have obtained relating power of lens to percentage of maximum response (as in our Fig. 4) are narrower than ours. That is, the mean dioptric range over which they obtained $80^{\circ}$ or better response was about $\pm 2 D$. whereas our narrowest range was $\pm 5 \mathrm{D}$. Again, we have no explanation for the discrepancy. but there are a number of differences between our experimental conditions and theirs that might be responsible. For example. their use of trial set lenses may have introduced optical problems not present with contact lenses: their more intense stimulus may have influenced more cones than ours; measurement of a cortical response instead of a retinal response may have somehow resulted in a "sharpening" effect: their use of gratings close to the limit of resolution. as determined in our experiments, may have affected the results: and finally (and perhaps most importantly), their rats were visually experienced during development whereas ours were not. Additional data in their paper suggest, in fact, that younger rats have a slightly broader dioptric range of maximum response than older rats.

\section{Depth of focus}

Focus has little effect on the number of spikes fired by rat retinal ganglion cells: in our hands, it neither increased nor decreased their responses over a very large range. The human eye with a $3 \mathrm{~mm}$ pupil tolerates changes of only about $\pm 1 / 3 \mathrm{D}$ before the image appears out of focus (Campbell, 1957). but, according to our experimental criteria at least, the rat eye with about the same pupil size can tolerate $\pm 14 \mathrm{D}$. more than 40 times more.

If $\pm 14 \mathrm{D}$ correction has little effect on the resolvability of a visual stimulus, then all objects from about $7 \mathrm{~cm}$ in front of the animal to optical infinity will be in focus. Similarly, the location of the image plane within the eye could vary $\pm 175 \mu \mathrm{m}$ (calculated from Block, 1969) and still maintain optimal focus. This depth of focus is many times larger than can be accounted for by the length of the rod outer segments in rats, which is about $20-25 \mu \mathrm{m}$ (Bonting, Caravaggio and Gouras, 1961: LaVail, 1976)

Our results provide empirical evidence that the depth of focus of the rat's eye is very large, confirming earlier anecdotal (Lashley, 1932) and inferential (Block, 1969) reports. Further confirmatory evidence for considerable depth of focus comes from Hughes 
(1977). His experiments on ganglion cell receptive field size show that if one uses a $20 \%$ increase in receptive field diameter to estimate depth of focus, then the depth is approximately $\pm 20 \mathrm{D}$ with a $0.3 \mathrm{~mm}$ pupil and about $\pm 6 \mathrm{D}$ with a fully dilated pupil. Given the differences in methodology these values are comfortingly close to our grating measures of depth of focus.

The depth of focus we measured is $4.5 \%$ of the total refractive power of the rat's eye $(324 \mathrm{D}$ : Block, 1969), whereas the depth of focus of the human eye is about $0.6 \%$ of its total refractive power $(58 \mathrm{D}$ : Davson. 1972). We argue elsewhere (Green et al, 1978) that depth of focus generally increases with decreasing size of the eye. and that simple calculations can reveal its magnitude.

\section{CONCLUSION}

The acuity of the dark-reared hooded rat is low, and it cannot be improved by moving the location of the focal plane relative to the retina. The lack of change in responses of retinal ganglion cells over $\pm 14 \mathrm{D}$ displacement $( \pm 175 \mu \mathrm{m}$ relative to the receptor plane) implies great depth of focus in the eye, and means that most visual stimuli, both experimental and natural, are effectively in good focus.

Acknowledgements-This work was supported by $\mathrm{NIH}$ grant EY 00379 to D.G.G. We thank the Contact Lens Clinic. University of Michigan Hospital for supplying the lenses, Edith Crofts and Kim Gifford for help with the typing, Rebecca Green for assistance with data analysis, and David Vogel for programming the computer.

\section{REFERENCES}

Block M. T. (1969) A note on refraction and image formation of the rat's eye. Vision Res. 9, 705-711.

Bonting S. L., Caravaggio L. L. and Gouras P. (1961) The rhodopsin cycle in the developing vertebrate retina. I. Relation of rhodopsin content, electroretinogram and rod structure of the rat. Expl Eye Res. 1, 14-24.

Brown J. E. and Rojas J. A. (1965) Rat retinal ganglion cells: Receptive field organization and maintained activity. J. Neurophysiol. 28, 1073-1090.

Campbell F. W. (1957) The depth of field of the human eye. Optica Acta 4, 158-164.

Campbell F. W. and Green D. G. (1965) Optical and retinal factors affecting visual resolution. J. Physiol. 181, 576-593.

Cicerone C. M. (1976) Cones survive rods in the lightdamaged eye of the albino rat. Science 194, 1183-1185.

Cicerone C. M. and Green D. G. (1977) Control of eye movements while recording from single units in the pigmented rat. Vision Res. 17, 985-987.

Davson H. (1972) The Physiology of the Eye. Academic Press, New York.

Enroth-Cugell C. and Robson J. G. (1966) The contrast sensitivity of retinal ganglion cells of the cat. J. Physiol. $187,517-552$.
Gesteland R. C.. Howland B.. Lettrin J. Y. and Pitts W. H. (1959) Comments on microelectrodes. Proc. Inst. Radio Engng 47, 1856-1862.

Glickstein M. and Millodot M. (1970) Retinoscopy and eye size. Science 163, 605-606.

Green D. G. (1971) Light adaptation in the rat retina: Evidence for two receptor mechanisms. Science 174, $598-600$.

Green D. G. (1973) Scotopic and photopic components of the rat electroretinogram. J. Physiol. 228. 781-797.

Green D. G. and Campbell F. W. (1965) Effect of focus on the visual response to a sinusoidally modulated spatial stimulus. J. opt. Soc. Am. 55. 1154-1157.

Green D. G.. Powers M. K. and Banks M. S. (1978) Depth of focus. eyesize and visual acuity. In preparation.

Green D. G.. Tong L. and Cicerone C. M. $(1977)$ Latera! spread of light adaptation in the rat retina. Vision Res. 17. 479-486.

Hermann G. (1958) Beiträge zur Physiologie des Rattenauges. Z. Tierspsychol. 15. 462-5is.

Hughes A. (1977) The refractive state of the rat eye. Vision Res. 17, 927-939.

Ikeda H. and Wright M. J. (1972) Differential effects of refractive errors and receptive field organization of central and peripheral ganglion cells. Vision Res. 12. $1465-1476$

Lashley K. S. (1930) The mechanism of vision III: The comparative visual acuity of pigmented and abino rats. J. genet. Psychol. 37, 481-484.

Lashley K. S. (1932) The mechanism of vision V: The structure and image-forming power of the rat's eye. $J$. comp. Psychol. 13, 173-200.

Lashley K.S. (1938) The mechanism of vision XV: Preliminary studies of the rat's capacity for detailed vision. $J$. gen. Psychol. 18, 123-193.

LaVail M. M. (1976) Rod outer segment disk shedding in rat retina: Relationship to cyclic lighting. Science 194. 1071-1074.

Levick W. R. (1972) Another tungsten microelectrode. Med. Biol. Engng 10, 510-515.

Massof R. W. and Chang F. W. (1972) A revision of the rat schematic eye. Vision Res. 12, 793-796.

Meyer D. L. and Schwassmann H. O. (1970) Electrophysiological method for determination of refractive state in Gish eyes. Vision Res. 10, 1301-1303.

Meyer G. E. and Salinsky M. C. (1977) Refraction of the rat: Estimation by pattern evoked visual cortical potentials. Vision Res. 17, 883-885.

Montero V. M., Brugge J. F. and Beitel R. E. (1968) Relation of the visual field to the lateral geniculate body of the albino rat. $J$. Neurophysiol. 31, 221-236

Partridge L. D. and Brown J. E. (1970) Receptive fields of rat retinal gangtion cells. Vision Res. $10.455-460$.

Schwassmann H. O. (1975) Refractive state, accommodation, and resolving power of the fish eve. In Vision in Fishes (edited by Ali M. A.). Plenum Press. New York.

Shaw C., Yinon U. and Auerbach E. (1975) Receptive fields and response properties of neurons in the rat visual cortex. Vision Res. 15, 203-208.

Siminoff R., Schwassmann H. O. and Kruger L. (1966) Electrophysiological study of the visual projection to the superior colliculus of the rat. J. comp. Neurol. 127, 435-444.

Wiesenfeld Z. and Branchek T. (1976) Refractive state and visual acuity in the hooded rat. Vision Res. 16, 823-827. 